\title{
Comparative study between cryotherapy and salicylic acid in the treatment of plantar warts in Erbil - Iraq
}

\begin{abstract}
Background and objective: Plantar warts are hard, grainy growths that usually appear on the heels or balls of feet. Plantar warts are caused by the human papillomavirus, usually self-limiting, but treatment is generally recommended to lessen symptoms, decrease duration, and reduce transmission. The study aimed to evaluate the clinical effectiveness of topical $40 \%$ salicylic acid in comparison to cryotherapy in the treatment of plantar wart.
\end{abstract}

Methods: This study was conducted from March 2015 to January 2016 on 70 patients with plantar wart who attended the consultation clinic of dermatology department in Rizgary teaching hospital. Patients were randomly allocated to two groups: cryotherapy treatment with liquid nitrogen every two or three weeks and self-application of salicylic acid daily.

Results: Sixty patients aged 12 to 60 years were included in the analysis at 13 weeks. Cure rates were $66.7 \%$ in the cryotherapy group and $80 \%$ in the salicylic acid group. A significant association was found between the duration of wart before treatment and cure rates $(P<0.001)$.

Conclusion: No difference in effectiveness between cryotherapy and topical salicylic acid $40 \%$ in the treatment of plantar warts was found.

Keywords: Cryotherapy; Salicylic acid; Plantar wart; Erbil.

\section{Introduction}

Plantar warts, also known as verruca plantaris, are benign epithelial tumors, caused by the human papillomavirus (HPV) occurring on the soler toes of the feet. On the soles, these are often painful from pressure when walking, due to their deep inward growth. Plantar warts are common in older children and young adults, accounting for $30 \%$ of cutaneous warts. Plantar warts are caused by HPV-1, 2, 4, 27 or $57 . .^{1-4} \mathrm{HPV}$ sorm a large group of closely related viruses, distinguished one from another on the basis of their DNA. To date, about 100 types have been recognized and characterized. All papillomavirus types have a tropism for stratified squamous epithelial cells, but they vary in their specificity for different anatomical sites. Papillomaviruses are small 50 to 55 -nm-diameter DNA viruses that infect squamous epithelia, causing cell proliferation. The commonest effect of HPV infection is the development of warts (verrucae). ${ }^{2}$ A plantar wart at first appears as a small shining 'sago-grain 'papule, but soon assumes the typical appearance of a sharply defined, rounded lesion, with a rough, keratotic surface surrounded by a smooth collar of a thickened horn. Individuals may be affected by a single or numerous lesions. ${ }^{2}$ The soft, pulpy cores are surrounded by a firm, horny ring. Over the surface of the plantar wart, most clearly if the top is shaved off, multiple small black points may be seen that represent dilated capillary loops within elongated dermal papillae. ${ }^{1}$ Pain is a common but variable symptom. It may be severe and disabling, but may be absent, and many warts are discovered only on routine inspection. ${ }^{2}$

* Rizgary Teaching Hospital, Erbil, Iraq. 
The duration of plantar warts is very variable. Spontaneous regression occurs sooner in children than in adults and is delayed if hyperhidrosis or orthopedic defects are present. In children before puberty, the average duration is probably less than a year, but in older children and adults a longer duration is not uncommon and persistence for several years is not exceptional. ${ }^{2}$ Plantar warts are usually self-limiting. ${ }^{2}$ Although most warts resolve within two years, some persist and become large and painful. ${ }^{5}$ Painful warts must be treated. A technique that does not cause scarring should be used; scars on the soles of the feet may be painful for years. ${ }^{6}$ In general, plantar warts are more refractory to any form of treatment than are common warts. Initial treatment usually involves daily application of salicylic acid in liquid, film, or plaster form after soaking, cryotherapy with a second freeze-thaw cycle, bleomycin injections, laser therapy, topical immunotherapy, $\mathrm{CO} 2$ laser, photodynamic therapy and surgical destruction with cautery or blunt dissection. The latter option should be reserved for failures with nonscarring techniques, since a plantar scar may be persistently painful. ${ }^{1}$ Salicylic acid (ortho-hydroxybenzoic acid) is a beta hydroxy acid agent. ${ }^{7}$ It is a firstline therapy that is usually chosen as its available over the counter. ${ }^{8}$ Salicylic acid has been extensively used in dermatologic therapy as a keratolytic agent. ${ }^{9}$ The mechanism by which it produces its keratolytic and other therapeutic effects is poorly understood. The drug may solubilize cell surface proteins that keep the stratum corneum intact, thereby resulting in desquamation of keratotic debris. ${ }^{9}$ It is a keratolytic agent that slowly destroys the virus-infected epidermis and may cause an immune response from the mild irritation caused by the salicylic acid. ${ }^{10}$ It is prepared in concentrations from $10 \%$ to $60 \%$. $^{10}$ The advantages of the over-the-counter salicylic acid include convenience, minimal expense, negligible pain and reasonable. The disadvantages are that results require weeks to months of treatment, and the patient must strictly adhere to instructions. ${ }^{11,12}$ Cryosurgery with liquid nitrogen $\left(-196^{\circ} \mathrm{C}\right)$ is a controlled frost bite, freezing that causes intracellular and extracellular ice crystals to form and the vascular stasis causes tissue anoxia\& necrosis. Liquid nitrogen is the cryogen of choice in dermatology. It is easy to store and use, environmentally friendly, nonflammable, inexpensive. ${ }^{13}$ The procedure may cause a little pain; the skin gets red swells and fine desquamation develop within several days. With deep freeze, blisters are produced. ${ }^{3}$ Cryotherapy cause separation of the epidermis and dermis. ${ }^{4}$ People with cold related conditions, such as cryoglobulinemia, cryofibrinogenemia, cold urticarial and Raynaud's disease should not be treated with cryotherapy. ${ }^{3}$ This study aimed to evaluate the clinical effectiveness of topical $40 \%$ salicylic acid in comparison with cryotherapy in the treatment of plantar wart. To the best of our knowledge, there hasn't been any similar study conducted in Erbil city.

\section{Methods}

A comparative study comparing two drugs in the treatment of plantar wart was conducted in the dermatology department of Rizgary Teaching Hospital in Erbil city, from March 2015 to January 2016. The study population involved 70 patients diagnosed clinically as having planter wart, they aged 12 years and above, both genders were involved. Patient's allergic to non-steroidal anti-inflammatory drugs, or if have any other allergies, diabetes, poor blood circulation (e.g., peripheral vascular disease), skin infection and irritation were excluded from the study. A detailed history was taken from each patient regarding age, gender, number of plantar warts and duration, associated pain, previous planter wart history and treatments, modalities of previous treatment (topical applications, cryotherapy, surgical removal and others) and history of recurrence. An informed 
verbal consent was obtained from each patient after an explanation of the objectives of the study. In case of minors, parents or guardians were asked for the consent. Patients were allocated randomly to one of the two groups:

-The salicylic acid group: Thirty five patients were included, they were randomized for self-treatment with $40 \%$ salicylic acid in Vaseline ointment, and were instructed how to apply the treatment. Patients were directed to fix an adhesive tape with a hole over the verruca and to squeeze a little ointment into the hole and directly on to the verruca and keep it overnight. The treatment was repeated daily after gently removing the dead part of the verruca for a maximum of eight weeks.

-The cryotherapy group: Thirty five patients were included; they were treated by cryotherapy with liquid nitrogen receiving a maximum of four to five treatments given two to three weeks apart. The liquid nitrogen was applied with a spray device in two freeze thaw cycles till freezing reached 2 to $3 \mathrm{~mm}$ beyond the lesion in each thaw cycle. All patients were followed every two weeks. The number of weeks required for salicylic application and the number of cryotherapy sessions were recorded till disappearance of the wart. The condition was registered as a complete response if restoration of normal skin was seen on close inspection.

Data management and statistical analysis:

Data were recorded on a specially designed questionnaire, and analyzed using the statistical package for the social sciences (version 22) and the results were compared between patients with different variables. Chi square and independent samples t-tests were performed to compare between the two groups. A $P$ value of $\leq 0.05$ was regarded statistically significant.

\section{Results}

The study population involved 70 patients; thirty five patients were included in the salicylic group and 35 patient in the cryotherapy group. Out of 70 patients with plantar warts, only five patients (14.3\%) from each group failed to complete the period of treatment and follow up. Of these 70 patients, $30(42.9 \%)$ patients were male and $40(57.1 \%)$ were female. Their age ranged from 12 to 60 years. The mean age of cryotherapy group was $22.54 \pm 8.72$ years and for salicylic acid group was $26.91 \pm 11.44$ years. The mean duration of wart in months was $(8.91 \pm 6.853,6.853 \pm 6.679)$ for cryotherapy group and salicylic acid group respectively. Fifty-six $(80 \%)$ patients had painful warts while $14(20 \%)$ patients had painless warts (Table 1). Those who had a previous history of plantar wart were $27(38.6 \%)$ and those with no previous history were 43 (61.4\%). Twenty-six $(96.3 \%)$ patients from those who had a previous history of wart had received previous treatment while only one patient did not receive any treatment (Table 1). 
Table 1: Basic characteristics of study groups.

\begin{tabular}{|c|c|c|c|c|}
\hline Variables & Categories & $\begin{array}{l}\text { Cryotherapy } \\
\text { No. (\%) }\end{array}$ & $\begin{array}{l}\text { Salicylic acid } \\
\text { No. (\%) }\end{array}$ & $\begin{array}{l}\text { Total } \\
\text { No. }(\%)\end{array}$ \\
\hline \multirow[t]{3}{*}{ Gender } & Male & $15(42.85)$ & $15(42.85)$ & $30(42.8)$ \\
\hline & Female & $20(57.15)$ & $20(57.15)$ & $40(57.15)$ \\
\hline & Total & $35(100)$ & $35(100)$ & $70(100)$ \\
\hline \multirow{3}{*}{$\begin{array}{l}\text { Association with } \\
\text { pain }\end{array}$} & Yes & $29(82.85)$ & $27(77.14)$ & $56(80)$ \\
\hline & No & $6(17.15)$ & $8(22.86)$ & $14(20)$ \\
\hline & Total & $35(100)$ & $35(100)$ & $70(100)$ \\
\hline \multirow[t]{3}{*}{ Previous history } & Yes & $12(34.28)$ & $15(45.71)$ & $27(38.57)$ \\
\hline & No & $23(65.72)$ & $20(54.29)$ & $43(61.43)$ \\
\hline & Total & $35(100)$ & $35(100)$ & $70(100)$ \\
\hline \multirow[t]{3}{*}{ Previous treatment } & Yes & 12(92.3) & $14(100)$ & $26(96.29)$ \\
\hline & No & $1(7.7)$ & $0(0)$ & $1(3.71)$ \\
\hline & Total & $13(100)$ & $14(100)$ & $27(100)$ \\
\hline \multirow{4}{*}{$\begin{array}{l}\text { Modalities of } \\
\text { previous treatment }\end{array}$} & Topical application & 11(84.6) & $8(57.2)$ & $19(70.4)$ \\
\hline & Cryotherapy & $1(7.7)$ & $3(21.4)$ & $4(14.8)$ \\
\hline & Surgical removal & $1(7.7)$ & $3(21.4)$ & $4(14.8)$ \\
\hline & Total & $13(100)$ & $14(100)$ & $27(100)$ \\
\hline \multirow{3}{*}{$\begin{array}{l}\text { History of } \\
\text { recurrence }\end{array}$} & Yes & $12(100)$ & $13(92.85)$ & $25(96.15)$ \\
\hline & No & $0(0)$ & $1(7.15)$ & $1(3.85)$ \\
\hline & Total & $12(100)$ & $14(100)$ & $26(100)$ \\
\hline Age (years) & Mean \pm SD & $22.54 \pm 8.729$ & $26.91 \pm 11.444$ & \\
\hline Duration (months) & Mean \pm SD & $8.91 \pm 6.853$ & $6.853 \pm 6.679$ & \\
\hline
\end{tabular}


There was no statistically significant association between the results of the two groups $(P>0.05)$. The percent of patients who were cured of warts or those who had their warts remained in their feet was very close to each other in both cryotherapy and salicylic acid study groups over different follow ups during the research time as shown in Table 2. The side effects of cryotherapy did not differ from salicylic acid, i.e. the number of participants who experienced pain, blistering, burning sensation or even those without any side effect did not differ in those who have been treated with cryotherapy or salicylic acid $(P>0.05)$, up to the $6^{\text {th }}$ week of therapy. On the eighth week of therapy, half participants of cryotherapy group developed pain or burning sensation after treatment, while none of the salicylic acid participants developed side effects $(P<0.05)$ as shown in Table 3.

Table 2: Response rate within 13 weeks of therapy.

\begin{tabular}{llccc}
\hline \multirow{2}{*}{ Week } & Plantar warts & $\begin{array}{c}\text { Cryotherapy } \\
\text { No. (\%) }\end{array}$ & $\begin{array}{c}\text { Salicylic acid } \\
\text { No. (\%) }\end{array}$ & P value \\
\hline Second & Still remaining & $32(94.1)$ & $33(94.3)$ & 0.97 \\
& Cured & $2(5.9)$ & $2(5.7)$ & \\
\multirow{2}{*}{ Fourth } & Still remaining & $26(78.8)$ & $26(74.3)$ & 0.66 \\
& Cured & $7(21.2)$ & $9(25.7)$ & \\
\multirow{2}{*}{ Sixth } & Still remaining & $16(53.3)$ & $12(40)$ & 0.43 \\
\multirow{3}{*}{ Eighth } & Cured & $14(46.7)$ & $18(60)$ & \multirow{2}{*}{0.41} \\
& Still remaining & $14(46.6)$ & $9(30)$ & \\
& Cured & $16(53.4)$ & $21(70)$ & 0.24 \\
\hline
\end{tabular}

Table 3: Association between study groups and side effects.

\begin{tabular}{llccc}
\hline \multirow{2}{*}{ Week } & Side effects & $\begin{array}{c}\text { Study samples } \\
\text { Cryotherapy } \\
\text { No. (\%) }\end{array}$ & $\begin{array}{c}\text { Salicylic acid } \\
\text { No. (\%) }\end{array}$ & P value \\
\hline Second & No & $14(43.8)$ & $18(54.5)$ & \\
& Pain or burning & $17(53.1)$ & $14(42.4)$ & 0.67 \\
& Blistering & $1(3.1)$ & $1(3)$ & \\
& Total & $32(100)$ & $33(100)$ & \\
Fourth & No & $17(65.4)$ & $18(69.2)$ & 0.75 \\
& Pain or burning & $8(30.8)$ & $7(26.9)$ & \\
& Blistering & $1(3.8)$ & $1(3.8)$ & \\
& Total & $26(100)$ & $26(100)$ & 0.61 \\
& No & $7(43.8)$ & $7(58.3)$ & \\
& Pain or burning & $9(56.3)$ & $5(41.7)$ & \\
& Total & $16(100)$ & $12(100)$ & 0.01 \\
\hline
\end{tabular}


Table 4 shows no statistically significant association between age and cure rates, while there was a significant association between the duration of wart before treatment and cure rates.

\section{Discussion}

In this study, the clinical effectiveness of cryotherapy with liquid nitrogen was compared with $40 \%$ salicylic acid for the treatment of plantar warts and it found no difference in effectiveness. The cure rate among the patients allocated to cryotherapy group was $66.7 \%$ compared with $80 \%$ among those treated with salicylic acid and this difference of $13.5 \%$ was not statistically significant. A similar finding was observed by other researchers. Our results were concordant with a study which compared cryotherapy with salicylic acid for the treatment of cutaneous warts where the cure rates among the participants with plantar warts treated with cryotherapy or salicylic acid were $30 \% 133 \%$ respectively, which was statistically non-significant. ${ }^{14}$ In another study' two separate trials were undertaken to compare liquid nitrogen with wart paint containing salicylic acid for the treatment of common hand warts and simple plantar warts, in the group with plantar wart, the cure rates of liquid nitrogen group versus salicylic acid group were $57.7 \% / 40.9 \%$ which was also statistically not significant. ${ }^{15}$ A meta-analysis of four trials comparing cryotherapy versus salicylic acid was done, in which 1106 abstracts related to clinical trials on cutaneous warts that were published from 1981 to 2011 were selected, no statistically significant difference in efficacy of cryotherapy from salicylic acid was demonstrated. ${ }^{16}$ The current trial differs from the previous studies with respect to the cure rate. In the current study cure rate among the patients allocated to cryotherapy group was $66.7 \%$ compared with $80 \%$ among those treated with salicylic acid. This difference of $13.3 \%$ was not statistically significant in a similar study neither treatment was very effective, with only $14 \%$ cure rate in the salicylic acid group and $14 \%$ in the cryotherapy group having complete clearance of plantar warts at 12 weeks showing a non-significant difference in effectiveness between the two treatments. ${ }^{17}$ A study done to assess the efficacy of local treatments for cutaneous warts in which they did systematic review of 50 randomized controlled trials, the best evidence was for topical treatments containing salicylic acid which showed a cure rate of $75 \%$ in patients compared with $48 \%$ in controls, while evidence for the efficacy of cryotherapy was limited in this study. ${ }^{18}$ In another trial on the treatment of plantar warts, they compared the efficacy of a compound contained Cantharidin-podophylotoxin-salicylic acid with cryotherapy, the concentration of salicylic acid was $30 \%$ in this study, and the result was that topical contained Cantharidin-podophylotoxin-salicylic acid was more effective than cryotherapy. ${ }^{19}$ The higher efficacy of salicylic acid could be due to combination with cantharidin and podophylotoxin. A study evaluating the topical treatments of cutaneous wart was done involving 85 trials. Meta-analysis was done to compare the difference between the efficacies of cryotherapy with salicylic acid at all sites except for genital warts, they demonstrated no significant

Table 4: Association between cure rates and age and duration of wart.

\begin{tabular}{llcccc}
\hline Measures & Treatment outcomes & N & Mean & S.D & $P$ value \\
\hline Age (years) & Still remaining & 16 & 28.00 & 9.661 & 0.17 \\
& Cured & 44 & 24.00 & 10.66 & \\
\multirow{2}{*}{ Duration (months) } & Still remaining & 16 & 13.19 & 7.591 & $<0.001$ \\
& Cured & 44 & 6.20 & 5.161 & \\
\hline
\end{tabular}


difference, except for one trial in the study showed better outcome of cryotherapy than placebo and salicylic acid. ${ }^{20}$ The differences in cure rate from other studies could be attributed to the different population recruited to the study and difference in the study design. In the current study, we excluded mosaic warts and those who had been treated within the past six months while another trial included both types of plantar wart (mosaic and non-mosaic verruca) and also did not exclude patients who took the previous treatment. ${ }^{17}$ Another factor may be attributed to the differences in cure rates is the duration of warts before treatment. ${ }^{14,15,20,21}$ In this study, a significant association was found between duration of warts before treatment and cure rates. There was also a difference in the age of the populations in our study in comparison to other studies which may have a rule in differences in cure rates. The mean ages of patients in our study were (22.54 \pm 8.729) years for cryotherapy patients and $(26.91 \pm 11.444)$ for salicylic acid patients. In another study the patients were younger, $59 \%$ were aged $7-15$ years and $41 \%$ were 16 years or more. ${ }^{15}$ Another study was performed on patients aged four years and older. ${ }^{14}$ In another study, the median age of patients was 15 years for cryotherapy patients and 13 years for salicylic acid patients. ${ }^{10}$ In the current study, there were no differences in side effects such as pain, blistering and scarring between the two treatment groups and this was accordant with others. ${ }^{14}$ In two other studies, the adverse effects were limited and not consistently reported but they were probably more common with cryotherapy than salicylic acid. ${ }^{16,20}$ The main limitations of this study included the small sample size and the application of salicylic acid by the patients at home as this may decrease the effectiveness of salicylic acid compared with cryotherapy which was applied by the investigator.

\section{Conclusion}

There was no statistically significant difference between salicylic acid and cryotherapy in the treatment of plantar warts. However and since salicylic acid can be easily applied by the patient at home and needs less attendance to hospital, we recommend the use of salicylic acid as the first choice treatment for plantar warts.

\section{Competing interests}

The authors declare that they have no competing interests.

\section{References}

1. James WD, Berger TC, Elestone DM. Viral diseases. In: Andrews Disease of the Skin: Clinical Dermatology. $10^{\text {th }}$ ed. Philadelphia: WB Saunders Company; 2006.

2. Sterling JC. Viral infections. In: Burns $T$, Breathnach S, Cox N, Griffiths C, eds. Rook's Text Book of Dermatology. $7^{\text {th }}$ ed. Italy: Blackwell Scientific Publication; 2004.

3. Elliot J A, Douglas R L. Warts. In: Wolff K, Goldsmith L A, Katz S, Gilchrest B A, Paller A S, Leffel J, Fitzpatrick TB (eds). Fitzpatrick's Dermatology in General Medicine. $7^{\text {th }}$ ed. NewYork: Mac Graw- Hill; 2008.

4. Kirnbauer R, Lenz P. Human. Papilloma viruses. In: Bolognia JL, Jorizzo JL, Schaffer JV. Editors. Dermatology. $3^{\text {rd }}$ ed. United States: Elsevier Saunders; 2012.

5. Sladden MJ, Johnston GA. Common skin infections in children. Clinical review. BMJ 2004; 329: (7457):95-9.

6. Habif TP. Wart. Herpes simplex and other viral infections. In: Clinical dermatology. $4^{\text {th }}$ ed. Philadelphia: Mosby; 2004.

7. Grimes PE. Salicylic acid. In: Tosti A, Grimes PE, De Padova MP, editors. Color Atlas of Chemical Peels. $2^{\text {nd }}$ ed. New York: Springer; 2012. P. 4957.

8. Sterling JC, Handfield-Jones S, Hudson PM. Guidelines for the management of cutaneous warts. Br J Dermatol 2001; 144:4-11.

9. Bertram G K, Susan B M, Anthony J T. Basics and clinical pharmacology. $12^{\text {th }}$ ed. McGraw-Hill; 2012.

10. Mittal A, Mehta S. Human papilloma virus and hepatitis A, B and C infections. In: Singal A, Grover C. editors. Comprehensive approach to infections in dermatology. London: Jaypee Brothers Medical Pub; 2016. P. 240-59.

11. Stulberg DL, Hutchinson AG. Molluscum contagiosum and warts. Am Fam Physician 2003; 67:1233-40.

12. Stulberg DL, Hutchinson AG. Physicians need more evidence on treatments of warts: 
in reply. Am Fam Physician 2003; 68:1714-6.

13. Zimmerman E, Crawford P. Cutaneous surgery. Am Fam Physician 2012; 86:1118-24.

14. Bruggink SC, Gussekloo J, Zaaijer K, Assendelft WJJ, Berger MY, Koes BW, et al. Cryotherapy with liquid nitrogen versus topical salicylic acid application for cutaneous warts in primary care: randomized controlled trial. CMAJ 2010:182 (15):1624-30.

15. Steele K, Irwin W. Liquid nitrogen and salicylic/ lactic acid paint in the treatment of cutaneous warts in general practice. $\mathrm{Br} \mathrm{J}$ Gen Pract 1988; 38 (311):256-8.

16. Micali G, Dall'Oglio F, Nasca MR. Topical treatments for cutaneous warts: an update. Expert Rev Dermatol 2013; 8(1):15-7.

17. Cockayne S, Hewitt C, Hicks K, Jayakody S, Kang, Ombs AR, et al. Cryotherapy versus salicylic acid for the treatment of planter wart. BMJ 2011; 342:3271.

18. Gibbs S, Harvey I, Sterling J, Stark R. Local treatments for cutaneous warts: systematic Review. BMJ 2002; 325(7362):461.

19. Kaçar N, Taşıı L, Korkmaz S, Ergin Ş, Erdoğan BŞ. Cantharidin-podophylotoxin- salicylic acid versus cryotherapy in the treatment of plantar warts: a randomized prospective study. J Eur Acad Dermatol Venereol 2012; 26(7):889-93.

20. Kwok CS, Gibbs S, Bennett C, Holland R, Abbott R. Topical treatments for cutaneous warts. Cochrane Database Syst Rev [abstract]; 2012:9.

21. Larsen $P Q$, Laurberg G. Cryotherapy of viral warts. J Dermatolog Treat 1996; 7(1):29-31. 